\title{
Assessment of the Antioxidant Activity and Quality Attributes of Yogurt Enhanced with Wild Herbs Extracts
}

\author{
Adriana Dabija, ${ }^{1}$ Georgiana Gabriela Codină, ${ }^{1}$ Sorina Ropciuc, ${ }^{1}$ Anca-Mihaela Gâtlan, \\ and Lăcrămioara Rusu (iD) ${ }^{2}$ \\ ${ }^{1}$ Faculty of Food Engineering, Stefan cel Mare University of Suceava, 13 Universitatii Street, Suceava 720229, Romania \\ ${ }^{2}$ Faculty of Engineering, Department of Food and Chemical Engineering, "Vasile Alecsandri" University of Bacau, \\ 157 Marasesti Street, Bacau 600115, Romania
}

Correspondence should be addressed to Lăcrămioara Rusu; lacraistrati04@yahoo.com

Received 2 February 2018; Accepted 8 April 2018; Published 14 May 2018

Academic Editor: Flora V. Romeo

Copyright $(2018$ Adriana Dabija et al. This is an open access article distributed under the Creative Commons Attribution License, which permits unrestricted use, distribution, and reproduction in any medium, provided the original work is properly cited.

The milk and yogurt products assortment has expanded by their enhancement with herb extracts, fibres extracted from byproducts of the fruit processing industry and also fresh spices. The aim of the present study was to test to what extent the addition of different herb extracts in yogurt will improve its qualitative characteristics and antioxidant activity. The aqueous extracts obtained from the four plants are considered in this study, respectively, thistle (Silybum marianum L.), hawthorn (Crataegus monogyna), sage (Salvia officinalis L.), and marjoram (Origanum vulgare L.). It was examined the effect of aqueous extracts prepared from four herbs $(0.25 / 1 \%)(\mathrm{w} / \mathrm{w})$ on yogurt's qualitative characteristics $(\mathrm{pH}$, titratable acidity, syneresis, water holding capacity, antioxidant activity, colour parameters, and rheological parameters) on both one day and 28 days after preparation. The final results show that the physicochemical and rheological properties of the yoghurt with herb extracts addition were improved compared to the control sample after 28 days of storage. The best results in terms of antioxidant properties were obtained when marjoram extract (Origanum vulgare L.) was incorporated. According to the data obtained, the best quality in terms of the physicochemical and rheological properties were in the case of the sample with $0.5 \%$ thistle extract (Silybum marianum L.) addition, while from point of view of the nutritional value, the best quality was in the case of the sample with $1 \%$ marjoram extract (Origanum vulgare L.) addition. The present study leads to the conclusion that yogurts enhanced with natural extracts may serve as functional food products, with significant health benefits.

\section{Introduction}

Yogurt is a fermented dairy product, and it is obtained and consumed massively in many countries and also highly appreciated, being considered important in human diet [1] Yogurt is a source of bioactive peptides which are formed during fermentation, but generally has a limited content of antioxidant activity. For this reason, several attempts to produce yogurts fortified with natural antioxidants from natural sources have a considerable interest and present a novel approach for product development $[2,3]$.

In this regard, extracts of many plants, herbs, fruits, and mushrooms rich in bioactive compounds are increasingly used as additive in yogurt for better nutritional and functional improvement. For example, extracts have been used for preparation of yogurt by many researchers: crude extracts from artichoke [4], grape and grape callus extracts $[5,6]$, tea infusions [7], Lycium barbarum water extract [8], seaweed extracts [9], spirulina [10], Pleurotus ostreatus aqueous extract [11], black tea extracts [12], and mangosteen rind (Garcinia mangostana Lin.) extract [13].

Herbal nutraceuticals are commonly used by people who seek alternative health care for prevention and treatment of disease. Therefore, in the recent past, there has been rapid growth in demand for herbal medicines in food products like yogurt.

Thistle (Silybum marianum L.), in family Asteraceae, is one of the important hepatoprotective crops. The active ingredient in milk thistle is silymarin, which is composed of flavonolignans that include silydianin, silychristin, and 
silybin [14]. Silymarin is a strong antioxidant, which can promote liver cell regeneration, reduce blood cholesterol, and help in the prevention of cancer $[15,16]$. Recently, silymarin has been widely used in commercial preparations, herbal teas, and as a biologically active ingredient in food supplements and medical products. These products are currently among the most rapidly growing sectors in the food product industry [17]. In addition, thistle fruit extracts have antiviral and antitumor activities, and their constituents are under intense research in the clinical therapy of cancer for chemoprevention, treatment, and amelioration of chemotherapy associated side effects $[18,19]$.

Hawthorn (Crataegus monogyna), a member of the Rosaceae family, is native to northern temperate zones, including those of North America, East Asia, Central Asia, and Europe [20,21]. Hawthorns grow as large shrubs or small trees and are usually armed with thorns. Many studies have demonstrated the beneficial effect of extracts of hawthorn fruits on the heart, blood circulation system, and they prevent myocardial dysfunction, improve coronary circulation, and possess hypolipidemic effects. Hawthorn contains a variety of biological active substances, among which polyphenols are a class of the most important and effective components [22, 23].

Sage (Salvia officinalis L.) is the most widespread species of the Lamiaceae family and encompasses about 900 species distributed throughout the world, which has been recognized for many medicinal plants with designated radical scavenger activity $[24,25]$. Its biomass before flowering has been extensively used not only in food processing as a spice but also in pharmaceutical preparations showing a broad range of biological and medicinal activities [26]. Traditionally, it has been widely used as herbal tea, spice, and food flavouring agent, while industrially it found application as fragrance agent in cosmetics, perfumery, and pharmaceutical industry. Different sage species are reported to show many biological activities and medicinal properties, such as antimicrobial, antioxidant, antibacterial, anti-inflammatory, antitumoral, anxiolytic, antidiabetic, antifungal, antiplasmodial, hypoglycaemic, and anticarcinogenic effects $[27,28]$.

Marjoram (Origanum vulgare L.), popularly known as oregano, is a very versatile plant and although it has been used in folk medicine as diaphoretic, carminative, antiinflammatory and tonic, only now it has been recognized for its antimicrobial property. Marjoram has been traditionally used for the treatment of gastrointestinal disturbances, cough, and bronchial diseases [29]. Marjoram is used in mouthwashes for oral hygiene and also applied topically to relieve symptoms of the common cold, such as nasal congestion. Several studies reported that extracts of marjoram had high antioxidant capacity mostly due to the polyphenolic compounds present in them. This herb has aroused interest among researchers in recent times because it shows biological activities including antimicrobial, antifungal, and antioxidant, and it may have the greatest potential for use in industrial food applications [30, 31].

This study proposed the use of aqueous extracts of some herbs in manufacture of yogurt, plants which are specific to spontaneous flora in Romania. The objective of this study was to investigate the effect of adding natural ingredients, such as herbs aqueous extracts (ranging concentration of $0.25 / 1 \%$ ), on the functionality and the structural properties of yogurt in comparison with a yogurt sample with no additions. The production of yogurt with antioxidant properties has a promising potential for utilization as functional product. The novelty of this study is the choice of these plants to be used as an addition in yogurts, the choice that has been made taking into account the health benefits of the bioactive compounds present in these plants.

\section{Materials and Methods}

2.1. Materials. The yogurt samples were obtained in laboratory conditions, using the following raw materials: cow's fresh milk with $3.5 \%$ fats, $4.5 \%$ carbohydrates, $3 \%$ proteins; lactic bacteria cultures (Lactobacillus bulgaricus and Streptococcus thermophillus) supplied by Danisco Romania S.R.L. The herbs used in the experiments were supplied by Fares Bio Vital Laboratories, Romania: thistle (Silybum marianum L.) $-Y_{\text {thistle, hawthorn (Crataegus monogyna) }} Y_{\text {hawthorn }}$, sage


gare L.) $-Y_{\text {marjoram. }}$. These herbs were milled and made into a fine powder. These herbs were stirred in $200 \mathrm{~mL}$ distilled water for 30 minutes at $70^{\circ} \mathrm{C}$, stored at $4 \pm 0.5^{\circ} \mathrm{C}$ for $12 \mathrm{~h}$, and filtered before use in yogurt production.

2.2. Yogurt Preparation. The production of yogurt with different formulations has been carried out by following a traditional process on cow's milk, including pasteurization at $90^{\circ} \mathrm{C}$ for 15 minutes, cooling to $41^{\circ} \mathrm{C}$, inoculation with $0.02 \%(\mathrm{w} / \mathrm{v})$ starter culture, dosing in packages (yogurt jars), adding herb extracts $(0 \%, 0.25 \%, 0.5 \%, 0.75 \%$ and $1.0 \%)(\mathrm{v} / \mathrm{v})$, and incubation at $41^{\circ} \mathrm{C}$, until the samples reached a $\mathrm{pH}$ of 4.6 [32]. The finished yogurt samples were stored at $4^{\circ} \mathrm{C} \pm 0.5^{\circ} \mathrm{C}$ for $24 \mathrm{~h}$, and then the analyses were performed in order to determine the physicochemical and rheological properties of samples.

\subsection{Physicochemical Analysis}

2.3.1. Titratable Acidity and $p H$ of Yogurt Samples. Titratable acidity of yogurt samples was determined by titration with $\mathrm{NaOH} 0.1 \mathrm{~N}$ and expressed in Thörner degrees. $\mathrm{pH}$ was measured with a $\mathrm{pH}$-meter (Mettler Toledo, Germany) in different stages of samples preparation: during fermentation, in finished product, and during storage.

2.3.2. Colour Evaluation. Colour parameters were determined using a CR400 Chroma Meter (Konica Minolta, Japan), with illuminate D65 as a reference: $L^{*}(100=$ white; 0 = black), $a^{*}$ (+, red; - green), $b^{*}$ (+ yellow; - blue). Samples were analyzed in triplicate.

2.3.3. Susceptibility to Syneresis (S) and Water Holding Capacity (WHC). Syneresis of the different yogurt samples was determined according to the methodology proposed by 
Barkallah et al. [10]. Therefore, $100 \mathrm{~mL}$ of each sample was placed in a funnel lined with Whatman filter paper number 1. After $6 \mathrm{~h}$ of drainage, the volume of whey was measured and the following formula was used to calculate susceptibility of syneresis:

$$
S=\left(\frac{V 1}{V 2}\right) \times 100,
$$

where $V 1$ is the volume of whey collected after drainage and $V 2$ is the volume of yogurt sample.

Water holding capacity of yogurt samples was determined by the centrifugation of $5 \mathrm{~g}$ of yogurt at $4500 \times \mathrm{g}$ for 15 minutes at $4^{\circ} \mathrm{C}$ (Spin MPW 223E Centrifuge, MPW Med. Instruments, Warsaw, Poland). The WHC was calculated according to the following equation:

$$
\operatorname{WHC}(\%)=\left(1-\frac{W 1}{W 2}\right) \times 100,
$$

where $W 1$ is the weight of whey after centrifugation and $W 2$ is the weight of yogurt [10].

\subsection{Determination of Antioxidant Activity}

2.4.1. Determination of the Total Polyphenol Content (TPC). Total polyphenol content was determined by an assay applied by Maksimović et al. [33]. TPC was expressed as mg gallic acid equivalent (GAE)/g.

2.4.2. Radical Scavenging Activity (RSA \%) Assay. Free radical scavenging activity (RSA) of the samples was measured using the method of Brand-Williams et al. [34]. $100 \mu \mathrm{m}$ of the sample solution was mixed with $2.9 \mathrm{~mL}$ of DPP (2,2-diphenyl-1-picrylhydrazyl) $60 \mu \mathrm{M}$ in methanol solution. The reaction mixture was left in the dark for 30 minutes, after which the absorbance was measured at $517 \mathrm{~nm}$ using a spectrophotometer (Spectrophotometer UV3600). Methanol was used as blank. Antioxidant activity was expressed as percentage inhibition of the DPPH radical and was determined by the following equation:

$$
\text { RSA } \%=\left[\frac{\left(A_{\text {control }}-A_{\text {sample }}\right)}{A_{\text {control }}}\right] \times 100 .
$$

2.5. Rheological Analysis. The Modular Advanced Rheometer System (Thermo Haake Mars, Germany) was used for studying the rheological properties of yogurt samples. The samples were allowed to rest for 10 minutes at $4^{\circ} \mathrm{C}$ on the $\mathrm{Ti}$ $40 \mathrm{~mm}$ geometry plate, before conducting the analyses. The samples were subjected to frequency dependency experiments from 0.1 to $10.0 \mathrm{~Hz}$, at $4^{\circ} \mathrm{C}$. The storage module $\left(G^{\prime}\right)$ and the loss module $\left(G^{\prime \prime}\right)$ at $1 \mathrm{~Hz}$ frequency were monitored. Also, there were conducted viscosity tests depending on time (10 minutes at a constant shear rate of $\left.100 \mathrm{~s}^{-1}\right)$. Three determinations of the two tests were conducted for each sample [32]. The Haake RheoWin Data Manager software was used for all the analyses to obtain the graphical representation of viscosity curves and dynamic tests $[35,36]$.

2.6. Statistical Analysis. The statistical analysis was done using XLSTAT (free trial version 2016, Addinsoft, Inc., Brooklyn, NY, USA) at a significance level at $p<0.05$. The graphical representation of the principal component analysis (PCA) allows the data to be analyzed on a two-dimensional $F 1 / F 2$ map and to identify the trends between variables at a significance level $p<0.05$. When two variables are far from the centre and close together, they correlate significantly. If they are on the opposite side of the centre, then they are significantly negatively correlated.

\section{Results and Discussion}

3.1. Physicochemical Characteristics and Antioxidant Activity. The yogurt samples were analyzed after two storage periods ( 1 and 28 days) at $4^{\circ} \mathrm{C}$. The results are shown in Table 1 and are expressed as the mean value of each analysed parameter of the samples, conducted in triplicate for the two storage periods considered.

An overall decrease of $\mathrm{pH}$ values of yogurt samples occurred during storage in refrigeration conditions. The $\mathrm{pH}$ for all the yogurt samples decreased during storage period, for example, in the case of $Y_{\text {thistle-1\% }}$ sample, the $\mathrm{pH}$ decreases from 4.62 in the first day to 4.25 in the last day of storage. The addition of herbs aqueous extracts did not seem to significantly affect the $\mathrm{pH}$ of the analysed samples compared to the control sample. The results presented above are in agreement with those obtained by Pelaes Vital et al., who reported that $\mathrm{pH}$ for control yogurt was approximately the same as $\mathrm{pH}$ of yogurts with Pleurotus ostreatus aqueous extract [11]. According to Caleja et al., the analysis of this parameter in yogurts is very important in terms of product safety [3].

Titratable acidity of all yogurt samples was between 88 and $111^{\circ} \mathrm{T}$ on the first day of storage, and between 101 and $116^{\circ} \mathrm{T}$, after 28 days of storage in refrigeration conditions for all the analyzed samples. Similarly, Barkallah et al. concluded that additional Spirulina platens increased the buffering capacity that required additional acid development by starter cultures during the whole storage period ( 28 days) at $4^{\circ} \mathrm{C}$ [10]. The results obtained shows all yoghurt samples with herb extracts have lower $\mathrm{pH}$ values $(p<0.05)$ and a higher acidity $(p<0.001)$ than the control sample. One explanation for this aspect is that the herb extracts improve the growth of bacteria contained in the yogurt samples.

Syneresis is considered by many researchers as one of the most important parameters indicating the quality of yogurt during storage [10, 36-39]. The control yogurt samples showed a higher syneresis compared to yogurt samples with different levels of herbs aqueous extracts addition, after the 28 days of the storage. The lowest syneresis after 28 days of storage was observed for yogurt with $0.50 \%$ thistle (Silybum marianum L.). In the same time, an improvement of the WHC parameter after 28 days of storage was observed for all yogurt samples containing extracts compared to the control 
TABLE 1: Physicochemical characteristics and antioxidant activity of yogurt samples.

\begin{tabular}{|c|c|c|c|c|c|c|c|}
\hline \multirow{2}{*}{ Storage day } & \multirow{2}{*}{ Sample } & \multicolumn{6}{|c|}{ Characteristics } \\
\hline & & $\mathrm{pH}$ & Acidity $(\mathrm{T})$ & Syneresis (\%) & WHC (\%) & TPC (mg.GAE/g) & RSA (\%) \\
\hline \multirow{17}{*}{ Day 1} & $Y_{\text {Control }}$ & $4.41 \pm 0.01$ & $105 \pm 0.2$ & $54.4 \pm 0.1$ & $35.77 \pm 0.1$ & $0.99 \pm 0.02$ & $10.56 \pm 0.1$ \\
\hline & $Y_{\text {thistle- } 0.25 \%}$ & $4.50 \pm 0.01$ & $101 \pm 0.1$ & $53.6 \pm 0.2$ & $32.44 \pm 0.1$ & $0.98 \pm 0.02$ & $10.14 \pm 0.1$ \\
\hline & $Y_{\text {thistle- } 0.50 \%}$ & $4.38 \pm 0.02$ & $107 \pm 0.2$ & $48.0 \pm 0.1$ & $34.11 \pm 0.3$ & $0.88 \pm 0.01$ & $12.80 \pm 0.1$ \\
\hline & $Y_{\text {thistle- } 0.75 \%}$ & $4.56 \pm 0.01$ & $97 \pm 0.1$ & $49.8 \pm 0.3$ & $34.56 \pm 0.1$ & $0.90 \pm 0.01$ & $11.02 \pm 0.2$ \\
\hline & $Y_{\text {thistle-1\% }}$ & $4.62 \pm 0.01$ & $88 \pm 0.1$ & $54.2 \pm 0.1$ & $30.78 \pm 0.1$ & $1.27 \pm 0.01$ & $12.67 \pm 0.1$ \\
\hline & $Y_{\text {hawthorn-0.25\% }}$ & $4.52 \pm 0.02$ & $100 \pm 0.1$ & $51.6 \pm 0.1$ & $34.86 \pm 0.1$ & $3.46 \pm 0.01$ & $19.23 \pm 0.1$ \\
\hline & $Y_{\text {hawthorn- } 0.50 \%}$ & $4.36 \pm 0.03$ & $111 \pm 0.1$ & $49.8 \pm 0.1$ & $36.04 \pm 0.3$ & $3.88 \pm 0.01$ & $21.60 \pm 0.1$ \\
\hline & $Y_{\text {hawthorn-0.75\% }}$ & $4.44 \pm 0.01$ & $106 \pm 0.3$ & $48.0 \pm 0.2$ & $35.60 \pm 0.1$ & $4.02 \pm 0.02$ & $32.02 \pm 0.2$ \\
\hline & $Y_{\text {hawthorn-1\% }}$ & $4.50 \pm 0.01$ & $104 \pm 0.1$ & $53.6 \pm 0.2$ & $31.28 \pm 0.1$ & $4.34 \pm 0.01$ & $33.38 \pm 0.1$ \\
\hline & $Y_{\text {sage- } 0.25 \%}$ & $4.49 \pm 0.01$ & $110 \pm 0.1$ & $55.0 \pm 0.1$ & $37.61 \pm 0.2$ & $2.18 \pm 0.01$ & $23.14 \pm 0.1$ \\
\hline & $Y_{\text {sage- } 0.50 \%}$ & $4.52 \pm 0.03$ & $102 \pm 0.3$ & $54.2 \pm 0.1$ & $35.02 \pm 0.1$ & $3.88 \pm 0.03$ & $22.30 \pm 0.1$ \\
\hline & $Y_{\text {sage- } 0.75 \%}$ & $4.51 \pm 0.01$ & $105 \pm 0.1$ & $54.8 \pm 0.1$ & $35.72 \pm 0.1$ & $4.17 \pm 0.01$ & $20.23 \pm 0.3$ \\
\hline & $Y_{\text {sage- } 1 \%}$ & $4.54 \pm 0.02$ & $101 \pm 0.1$ & $54.8 \pm 0.1$ & $33.92 \pm 0.1$ & $4.08 \pm 0.01$ & $21.21 \pm 0.1$ \\
\hline & $Y_{\text {marjoram- } 0.25 \%}$ & $4.45 \pm 0.3$ & $107 \pm 0.2$ & $52.4 \pm 0.1$ & $33.21 \pm 0.3$ & $3.21 \pm 0.03$ & $33.14 \pm 0.1$ \\
\hline & $Y_{\text {marjoram- } 0.50 \%}$ & $4.51 \pm 0.01$ & $97 \pm 0.1$ & $53.6 \pm 0.3$ & $30.90 \pm 0.1$ & $3.88 \pm 0.01$ & $42.30 \pm 0.1$ \\
\hline & $Y_{\text {marjoram- } 0.75 \%}$ & $4.48 \pm 0.01$ & $108 \pm 0.1$ & $52.0 \pm 0.1$ & $30.38 \pm 0.1$ & $5.11 \pm 0.01$ & $34.23 \pm 0.1$ \\
\hline & $Y_{\text {marjoram-1\% }}$ & $4.41 \pm 0.01$ & $106 \pm 0.2$ & $48.8 \pm 0.3$ & $31.67 \pm 0.1$ & $5.28 \pm 0.01$ & $41.21 \pm 0.1$ \\
\hline \multirow{17}{*}{ Day 28} & $Y_{\text {Control }}$ & $4.20 \pm 0.01$ & $119 \pm 0.1$ & $58.4 \pm 0.1$ & $33.72 \pm 0.1$ & $0.36 \pm 0.01$ & $8.12 \pm 0.3$ \\
\hline & $Y_{\text {thistle- } 0.25 \%}$ & $4.28 \pm 0.02$ & $116 \pm 0.1$ & $48.3 \pm 0.1$ & $45.17 \pm 0.1$ & $1.46 \pm 0.02$ & $12.67 \pm 0.1$ \\
\hline & $Y_{\text {thistle- } 0.50 \%}$ & $4.26 \pm 0.03$ & $114 \pm 0.1$ & $45.6 \pm 0.1$ & $45.41 \pm 0.3$ & $1.12 \pm 0.01$ & $19.03 \pm 0.2$ \\
\hline & $Y_{\text {thistle- } 0.75 \%}$ & $4.29 \pm 0.03$ & $110 \pm 0.1$ & $48.4 \pm 0.1$ & $45.24 \pm 0.1$ & $0.96 \pm 0.01$ & $10.52 \pm 0.1$ \\
\hline & $Y_{\text {thistle-1\% }}$ & $4.25 \pm 0.02$ & $102 \pm 0.3$ & $50.6 \pm 0.1$ & $41.35 \pm 0.1$ & $1.92 \pm 0.02$ & $12.04 \pm 0.2$ \\
\hline & $Y_{\text {hawthorn- } 0.25 \%}$ & $4.32 \pm 0.01$ & $105 \pm 0.3$ & $53.6 \pm 0.1$ & $37.77 \pm 0.2$ & $3.82 \pm 0.01$ & $19.03 \pm 0.2$ \\
\hline & $Y_{\text {hawthorn- } 0.50 \%}$ & $4.31 \pm 0.01$ & $101 \pm 0.1$ & $55.6 \pm 0.1$ & $37.73 \pm 0.1$ & $4.46 \pm 0.01$ & $23.74 \pm 0.1$ \\
\hline & $Y_{\text {hawthorn- } 0.75 \%}$ & $4.30 \pm 0.01$ & $107 \pm 0.2$ & $56.0 \pm 0.1$ & $38.15 \pm 0.1$ & $4.68 \pm 0.01$ & $30.76 \pm 0.1$ \\
\hline & $Y_{\text {hawthorn-1\% }}$ & $4.29 \pm 0.02$ & $107 \pm 0.2$ & $54.0 \pm 0.1$ & $35.43 \pm 0.2$ & $5.12 \pm 0.01$ & $33.49 \pm 0.2$ \\
\hline & $Y_{\text {sage-0.25\% }}$ & $4.35 \pm 0.02$ & $105 \pm 0.1$ & $55.8 \pm 0.2$ & $36.80 \pm 0.2$ & $2.72 \pm 0.01$ & $29.03 \pm 0.1$ \\
\hline & $Y_{\text {sage- } 0.50 \%}$ & $4.33 \pm 0.02$ & $108 \pm 0.1$ & $54.0 \pm 0.1$ & $37.56 \pm 0.3$ & $3.36 \pm 0.03$ & $22.84 \pm 0.1$ \\
\hline & $Y_{\text {sage- } 0.75 \%}$ & $4.34 \pm 0.01$ & $110 \pm 0.2$ & $54.4 \pm 0.3$ & $35.47 \pm 0.2$ & $3.40 \pm 0.01$ & $20.52 \pm 0.1$ \\
\hline & $Y_{\text {sage- } 1 \%}$ & $4.28 \pm 0.03$ & $116 \pm 0.2$ & $55.0 \pm 0.1$ & $39.32 \pm 0.1$ & $4.17 \pm 0.02$ & $20.32 \pm 0.3$ \\
\hline & $Y_{\text {marjoram- } 0.25 \%}$ & $4.30 \pm 0.03$ & $107 \pm 0.1$ & $51.8 \pm 0.1$ & $38.33 \pm 0.1$ & $3.42 \pm 0.01$ & $33.12 \pm 0.1$ \\
\hline & $Y_{\text {marjoram- } 0.50 \%}$ & $4.29 \pm 0.02$ & $110 \pm 0.1$ & $54.0 \pm 0.2$ & $39.04 \pm 0.1$ & $4.16 \pm 0.02$ & $40.50 \pm 0.1$ \\
\hline & $Y_{\text {marjoram- } 0.75 \%}$ & $4.30 \pm 0.01$ & $105 \pm 0.1$ & $55.0 \pm 0.1$ & $35.74 \pm 0.2$ & $5.40 \pm 0.01$ & $38.53 \pm 0.1$ \\
\hline & $Y_{\text {marjoram-1\% }}$ & $4.30 \pm 0.02$ & $106 \pm 0.2$ & $56.8 \pm 0.1$ & $35.74 \pm 0.1$ & $6.30 \pm 0.01$ & $42.09 \pm 0.2$ \\
\hline
\end{tabular}

samples. The best results were obtained for the $0.5 \%$ thistle (Silybum marianum L.) addition.

The factor that influencing these parameters, as have been shown by Barkallah et al. and other researchers, is the ability of proteins to retain water and milk fat cells in the structure of yogurt [10,36-39].

The results for total polyphenol content in the analyzed period ( $0-28$ days) varied in yogurt depending on the type of herb extract that was used. The best results were obtained for the yogurt with marjoram extracts addition; in this case, the TPC level reaching up to $6.30 \mathrm{mg}$ GAE/g during storage.

The yogurt samples with extracts of hawthorn (Crataegus monogyna) and sage (Salvia officinalis L.) were also rich in polyphenols, and the obtained results show values of $5.12 \mathrm{mg}$ $\mathrm{GAE} / \mathrm{g}$ and $4.17 \mathrm{mg} \mathrm{GAE} / \mathrm{g}$. The total polyphenol content in yogurt samples increases during storage. The total content of polyphenols in the analyzed samples is variable, and the correlation ratio $\left(r^{2}=0.139\right.$ and $\left.r^{2}=0.091\right)$ indicates a scattered distribution of the data. The best results were obtained for samples with marjoram (Origanum vulgare L.) extracts, which is also noted in the samples with sage (Salvia officinalis L.) extracts.
The results of the antioxidant activity correlate with the total content of polyphenols. High antioxidant activity is noted in yogurts with the addition of marjoram extracts both on the first day and on the last day of storage. Antioxidant activity was preserved during storage and even increased in some samples. It can be appreciated that lactic acid and herbal extracts affect the stability of the product over time. According by Muniandy et al., the inclusion of herb extracts prior to bacterial fermentation significantly increased the $(p<0.05)$ antioxidant activity compared to milk alone [12]. This could be attributed to the high content of flavonoids in herb extracts. Similar studies describe that the antioxidant activity of yogurts was enhanced by the presence of natural extracts $[3,14,16,22,23,25,29]$.

The obtained values of colour parameters according to the CIE colour scale are presented in Table 2, for all analysed yogurt samples. The incorporation of the herbs aqueous extracts did not change the colour parameters of the samples. In a similar study, performed by Chouchouli et al., it was shown that the fortification of yogurt with grape seed extract did not affect the colour of the yogurts, and changes were not visually detected [6]. The same aspect was observed 
TABLE 2: Colour parameters of the yogurt with different herb extracts.

\begin{tabular}{|c|c|c|c|c|c|c|c|}
\hline \multirow{2}{*}{ Storage day } & \multirow{2}{*}{ Sample } & \multicolumn{6}{|c|}{ Colour parameters } \\
\hline & & $L^{*}$ & $a^{*}$ & $b^{*}$ & $C_{\mathrm{ab}}^{*}$ & $h_{\mathrm{ab}}^{*}$ & $\Delta E^{*}$ \\
\hline \multirow{17}{*}{ Day 1} & $Y_{\text {Control }}$ & 84.91 & -6.89 & 12.61 & 14.37 & 118.65 & - \\
\hline & $Y_{\text {thistle- } 0.25 \%}$ & 83.85 & -6.67 & 11.55 & 13.34 & 120.01 & 1.52 \\
\hline & $Y_{\text {thistle- }-0.50 \%}$ & 78.8 & -6.29 & 10.87 & 12.56 & 120.06 & 6.38 \\
\hline & $Y_{\text {thistle}-0.75 \%}$ & 78.74 & -6.21 & 10.8 & 12.46 & 119.90 & 6.47 \\
\hline & $Y_{\text {thistle- } 1 \%}$ & 74.27 & -5.83 & 9.97 & 11.55 & 120.32 & 11.01 \\
\hline & $Y_{\text {hawthorn- } 0.25 \%}$ & 78.59 & -6.08 & 10.71 & 12.32 & 119.58 & 6.65 \\
\hline & $Y_{\text {hawthorn- }-0.50 \%}$ & 77.99 & -6.09 & 10.88 & 12.47 & 119.24 & 7.18 \\
\hline & $Y_{\text {hawthorn- }-0.75 \%}$ & 77.47 & -5.99 & 10.84 & 12.3849 & 118.9243 & 7.70 \\
\hline & $Y_{\text {hawthorn-1\% }}$ & 75.23 & -5.65 & 10.61 & 12.02059 & 118.036 & 9.96 \\
\hline & $Y_{\text {sage- } 0.25 \%}$ & 85.1 & -6.77 & 12.3 & 14.04005 & 118.8287 & 0.38 \\
\hline & $Y_{\text {sage- }-0.50 \%}$ & 84.56 & -6.27 & 13.01 & 14.44206 & 115.7311 & 0.82 \\
\hline & $Y_{\text {sage- }-0.75 \%}$ & 80.99 & -5.82 & 12.78 & 14.04282 & 114.4845 & 4.07 \\
\hline & $Y_{\text {sage-1\% }}$ & 84.62 & -6 & 13.57 & 14.83728 & 113.8527 & 1.34 \\
\hline & $Y_{\text {marjoram- } 0.25 \%}$ & 75.43 & -5.47 & 10.46 & 11.80392 & 117.6071 & 9.82 \\
\hline & $Y_{\text {marjoram- } 0.50 \%}$ & 75.32 & -5.14 & 10.77 & 11.93367 & 115.5129 & 9.92 \\
\hline & $Y_{\text {marjoram- }-0.75 \%}$ & 74.78 & -4.86 & 10.99 & 12.01664 & 113.856 & 10.46 \\
\hline & $Y_{\text {marjoram-1\% }}$ & 76.06 & -4.92 & 11.34 & 12.36131 & 113.4542 & 9.16 \\
\hline \multirow{17}{*}{ Day 28} & $Y_{\text {Control }}$ & 97.97 & -6.04 & 9.6 & 11.34 & 122.18 & - \\
\hline & $Y_{\text {thistle- }-0.25 \%}$ & 86.02 & -7.26 & 11.92 & 13.96 & 121.34 & 12.23 \\
\hline & $Y_{\text {thistle- }-0.50 \%}$ & 85.34 & -7.21 & 11.81 & 13.84 & 121.40 & 12.88 \\
\hline & $Y_{\text {thistle- } 0.75 \%}$ & 82.52 & -6.75 & 11.68 & 13.49 & 120.02 & 15.61 \\
\hline & $Y_{\text {thistle-1\% }}$ & 86.35 & -7.25 & 12.19 & 14.18 & 120.74 & 11.97 \\
\hline & $Y_{\text {hawthorn-0.25\% }}$ & 81.09 & -6.58 & 11.25 & 13.03 & 120.32 & 16.97 \\
\hline & $Y_{\text {hawthorn- } 0.50 \%}$ & 78.71 & -6.27 & 11.23 & 12.86 & 119.18 & 19.33 \\
\hline & $Y_{\text {hawthorn- } 0.75 \%}$ & 83.87 & -6.79 & 12.28 & 14.0322 & 118.9396 & 14.37 \\
\hline & $Y_{\text {hawthorn-1\% }}$ & 83.66 & -6.67 & 12.33 & 14.01848 & 118.4115 & 14.58 \\
\hline & $Y_{\text {sage- } 0.25 \%}$ & 85.52 & -6.95 & 12.23 & 14.06682 & 119.6085 & 12.76 \\
\hline & $Y_{\text {sage- } 0.50 \%}$ & 82.49 & -6.44 & 12.08 & 13.68941 & 118.0626 & 15.68 \\
\hline & $Y_{\text {sage- }-0.75 \%}$ & 84.13 & -6.3 & 12.62 & 14.10512 & 116.5287 & 14.17 \\
\hline & $Y_{\text {sage- } 1 \%}$ & 85.17 & -6.43 & 13.09 & 14.584 & 116.1609 & 13.27 \\
\hline & $Y_{\text {marjoram- }-0.25 \%}$ & 86.21 & -6.61 & 12.48 & 14.12241 & 117.9078 & 12.12 \\
\hline & $Y_{\text {marjoram- } 0.50 \%}$ & 85.52 & -6.3 & 12.68 & 14.15883 & 116.4203 & 12.83 \\
\hline & $Y_{\text {marjoram- }-0.75 \%}$ & 83.88 & -6.03 & 12.78 & 14.13115 & 115.2594 & 14.44 \\
\hline & $Y_{\text {marjoram-1\% }}$ & 80.44 & -5.43 & 12.45 & 13.58261 & 113.5642 & 17.77 \\
\hline
\end{tabular}

by Caleja et al. in the case of chamomile decoction addition in yogurt [3].

3.2. Evaluation of the Rheological Properties. Figures 1-4 show the evolution of samples' viscosity as a function of time at a constant shear rate of $100 \mathrm{~s}^{-1}$, for each storage period. This analysis showed the thixotropic characteristics of yogurt samples, which showed a reduction of viscosity in time, in accordance with the data presented in the literature. Several studies confirm that the yogurt is a thixotropic fluid, for example, Mathias et al. [40], Sidor et al. [35], and Sanz et al. [41]. In day 1 of storage, all fortified samples, independent of the amount of herb extract added, showed lower viscosity values than the control sample. However, the graphical representation showed higher viscosity values of fortified samples in the 28th day of storage comparing with the control sample. Sidor et al., evaluating the effect of sea buckthorn powder addition in yogurt, also observed that increasing the dose promoted the formation of a more viscous product [35].
The mechanical spectra obtained for the analyzed samples are shown in Figures 5-8. It can be observed that the form of the spectra was typical for weak gels, in both monitored storage times, with consistency module values $\left(G^{\prime}\right)$ slightly higher than those of firmness module values $\left(G^{\prime \prime}\right)$. Same trend regarding the viscoelastic properties of yogurt was observed by Sanz et al., when studying the effect of yogurt enrichment with fibers obtained from the nonedible part of asparagus shoots [41]. Also, the incorporation of all types of herb extracts produced an increase in the value of both modules in comparison with the control sample, which can be observed, especially, in the 28th day of storage.

3.3. Statistical Analysis. The principal component analysis (PCA) was used to illustrate the relationship between the physicochemical characteristics, the polyphenols content, and the antioxidant activity in yogurt samples. The obtained results for PCA are shown in Figures 9 and 10.

The addition of $1 \%$ hawthorn extract, $0.75 \%$ marjoram extract, and $0.75 \%$ sage has a significant positive influence on 


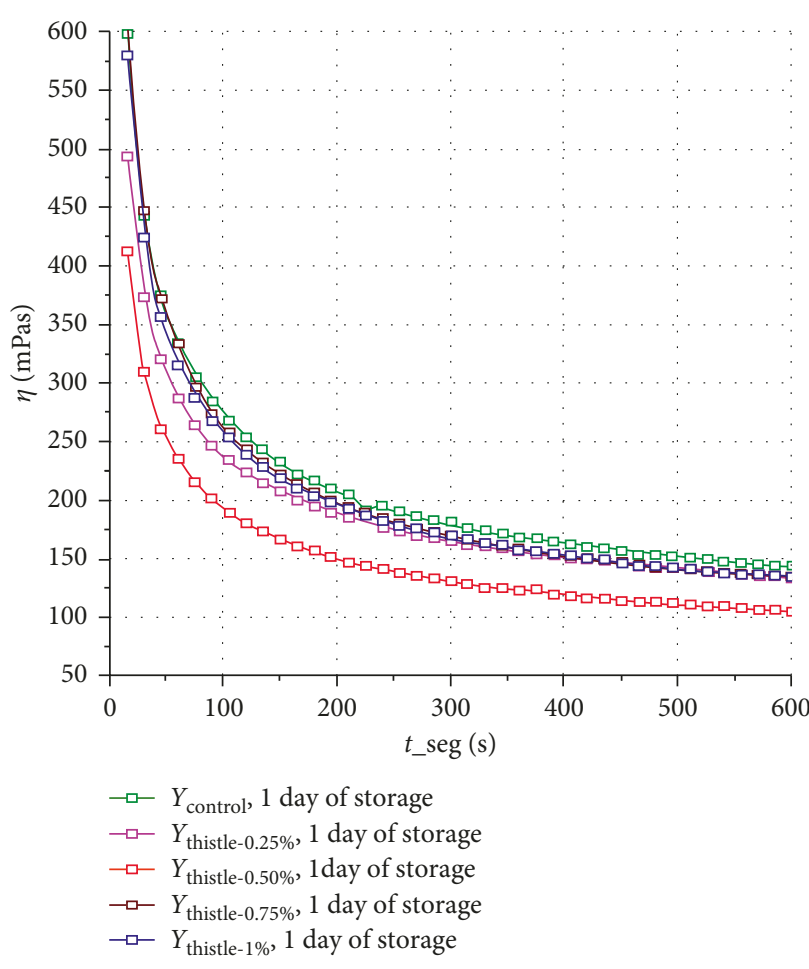

(a)

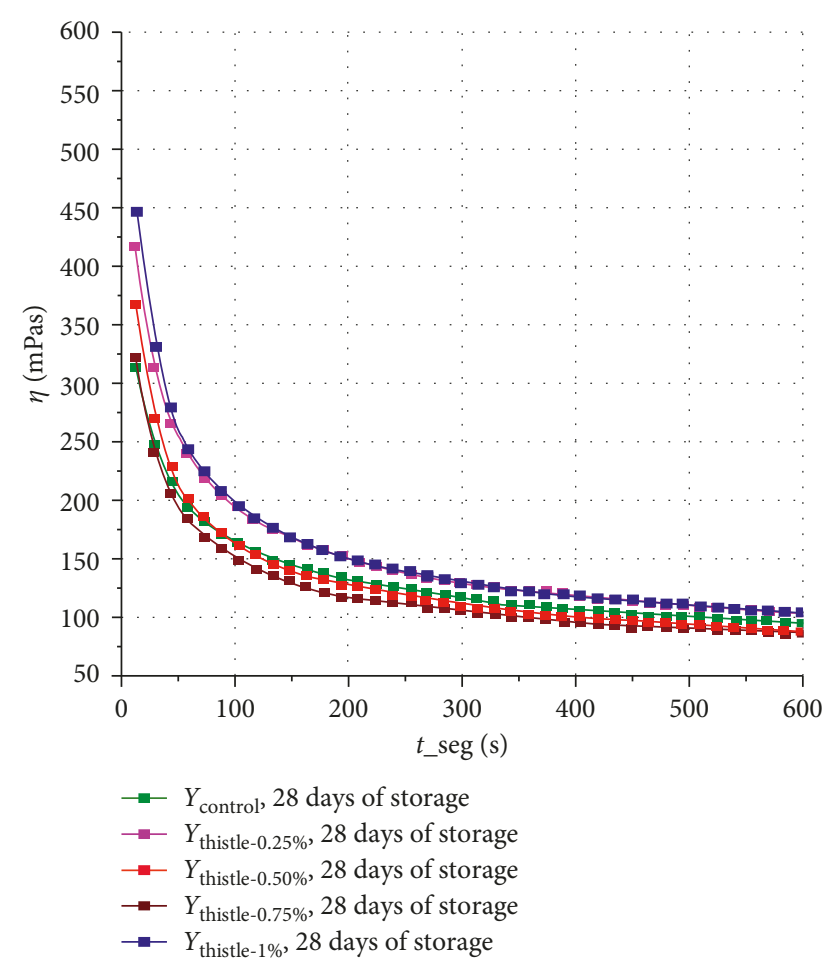

(b)

FIgURE 1: Curve of viscosity versus time of testing thixotropy of yogurt with thistle (Silybum marianum L.) extract: (a) 1 day of storage; (b) after 28 days of storage.

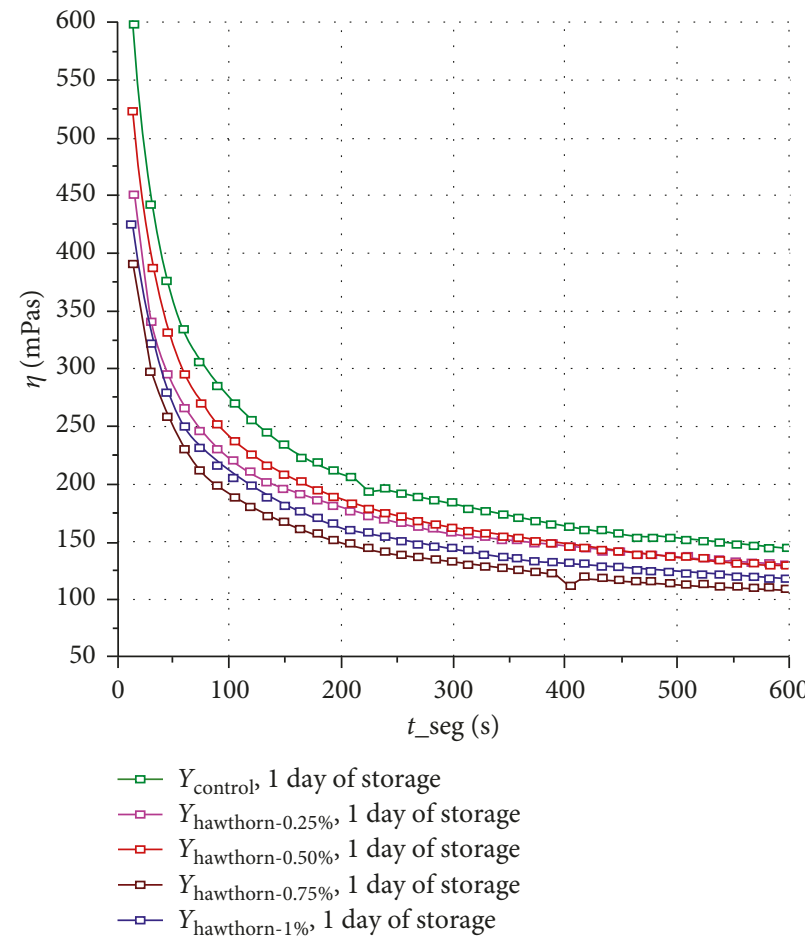

(a)

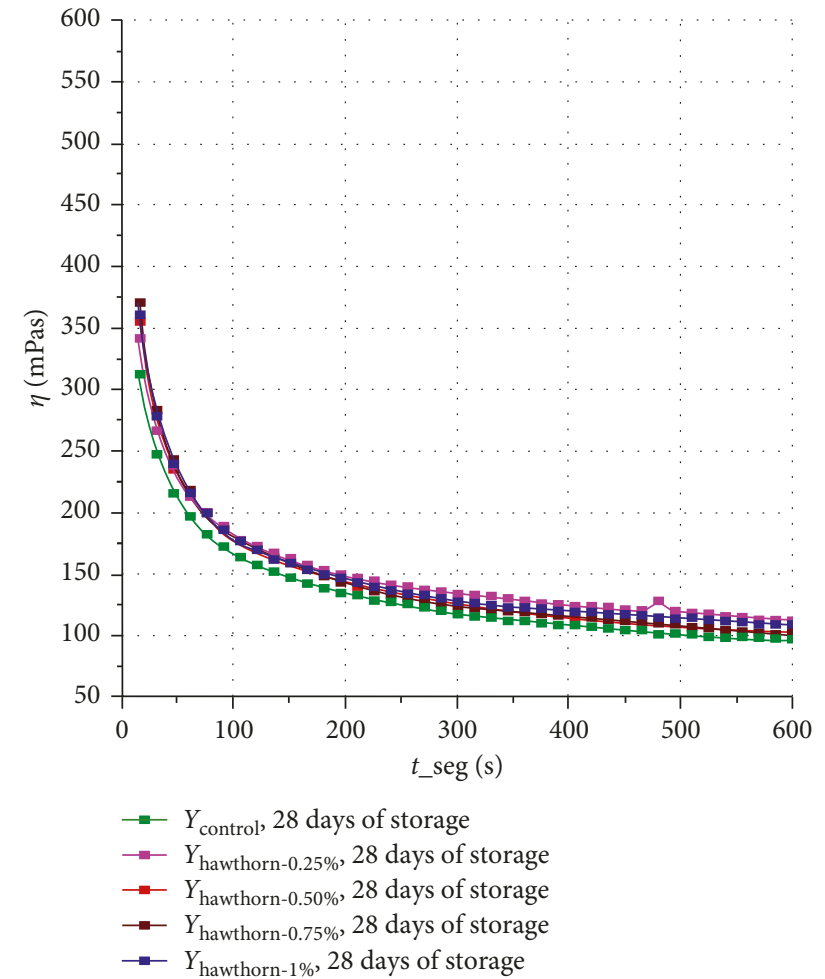

(b)

Figure 2: Curve of viscosity versus time of testing thixotropy of yogurt with hawthorn (Crataegus monogyna) extract: (a) 1 day of storage; (b) after 28 days of storage. 


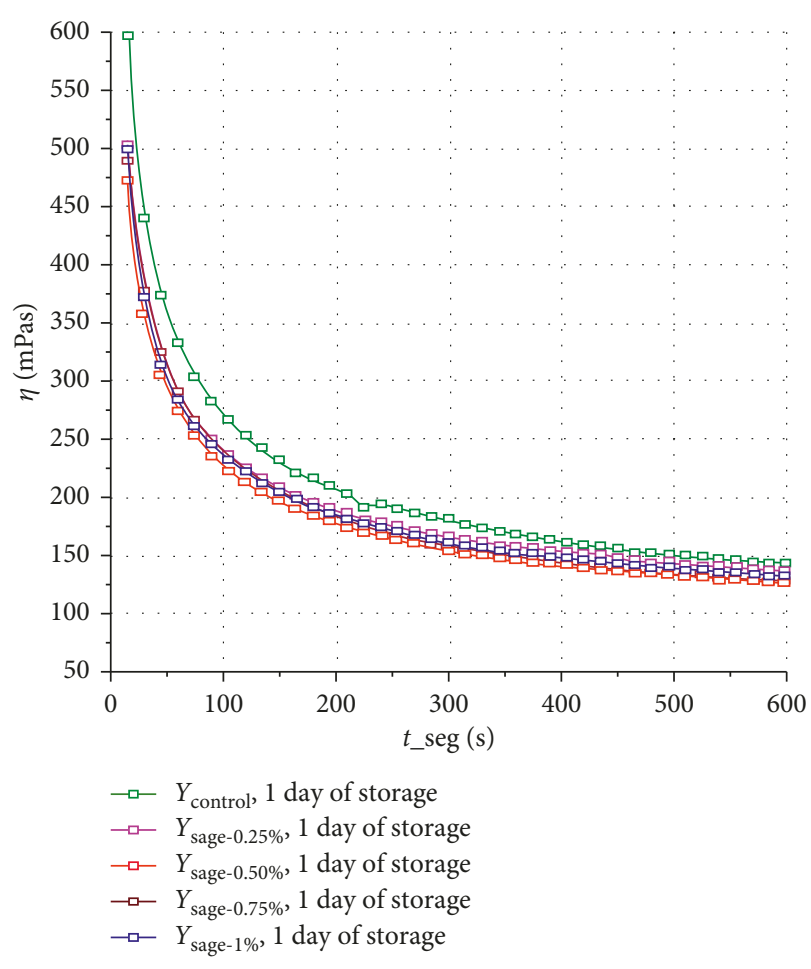

(a)

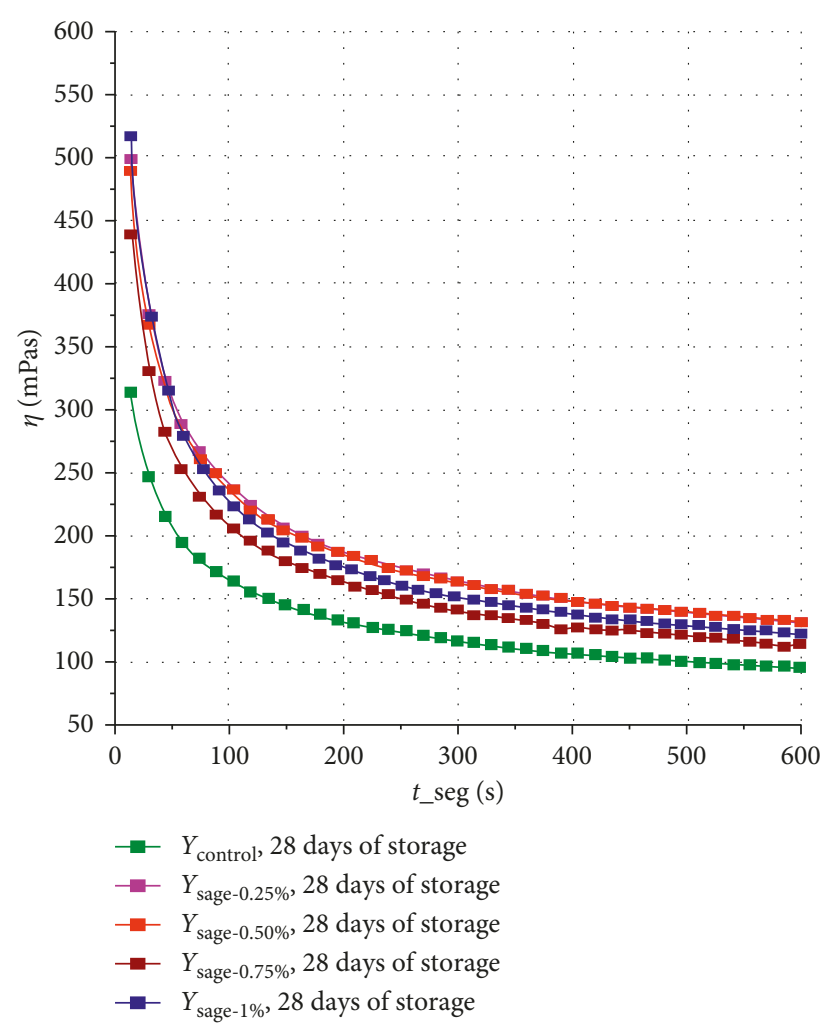

(b)

Figure 3: Curve of viscosity versus time of testing thixotropy of yogurt with sage (Salvia officinalis L.) extract: (a) 1 day of storage; (b) after 28 days of storage.

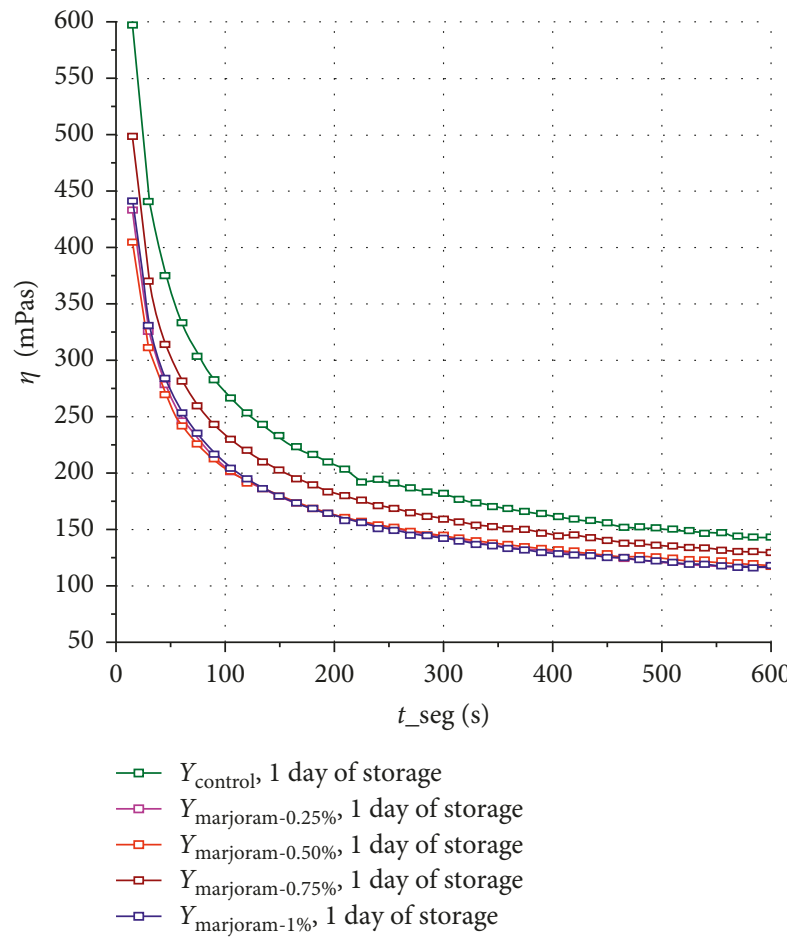

(a)

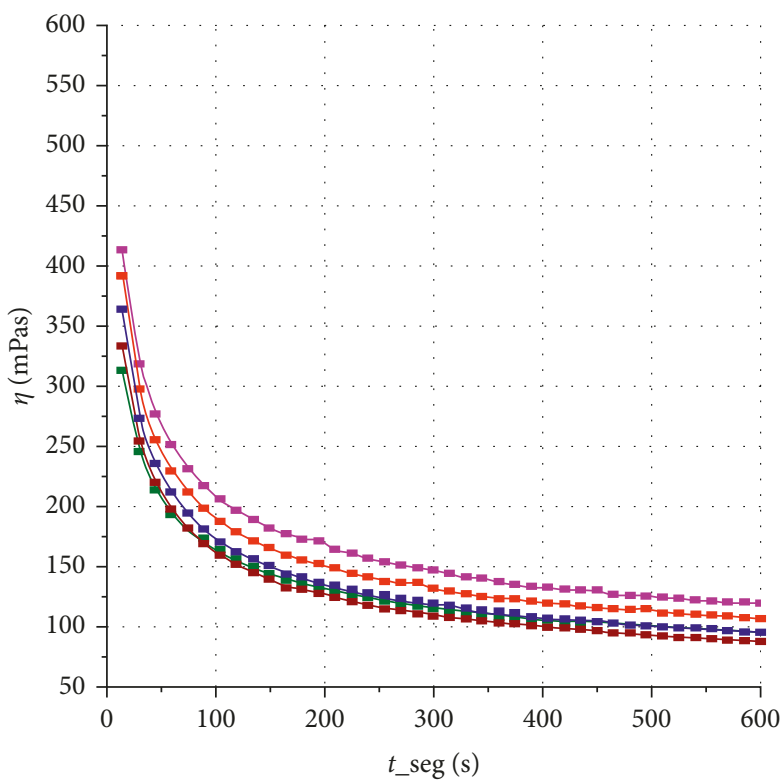

- $Y_{\text {control }} 28$ days of storage

$\rightarrow-Y_{\text {marjoram-0.25\% }}, 28$ days of storage

$\rightarrow-Y_{\text {marjoram- } 0.50 \%}, 28$ days of storage

$\rightarrow Y_{\text {marjoram- } 0.75 \%}, 28$ days of storage

$\rightarrow-Y_{\text {marjoram- } 1 \%}, 28$ days of storage

(b)

FiguRE 4: Curve of viscosity versus time of testing thixotropy of yogurt with marjoram (Origanum vulgare L.) extract: (a) 1 day of storage; (b) after 28 days of storage. 

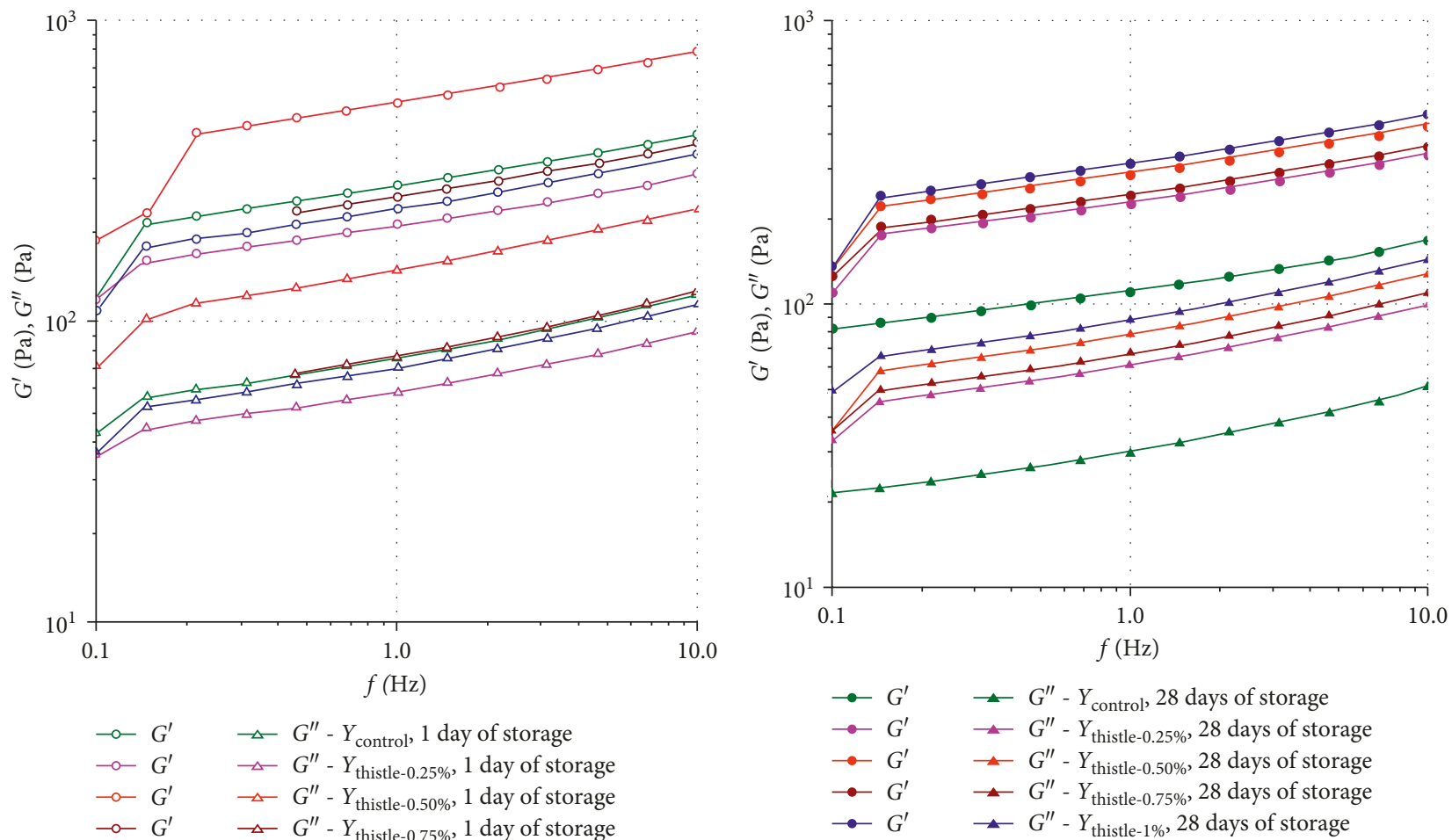

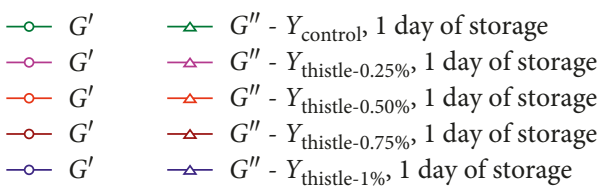

(a)

(b)

FIgURE 5: Viscoelastic properties of yogurt with thistle (Silybum marianum L.) extract: (a) 1 day of storage; (b) after 28 days of storage.
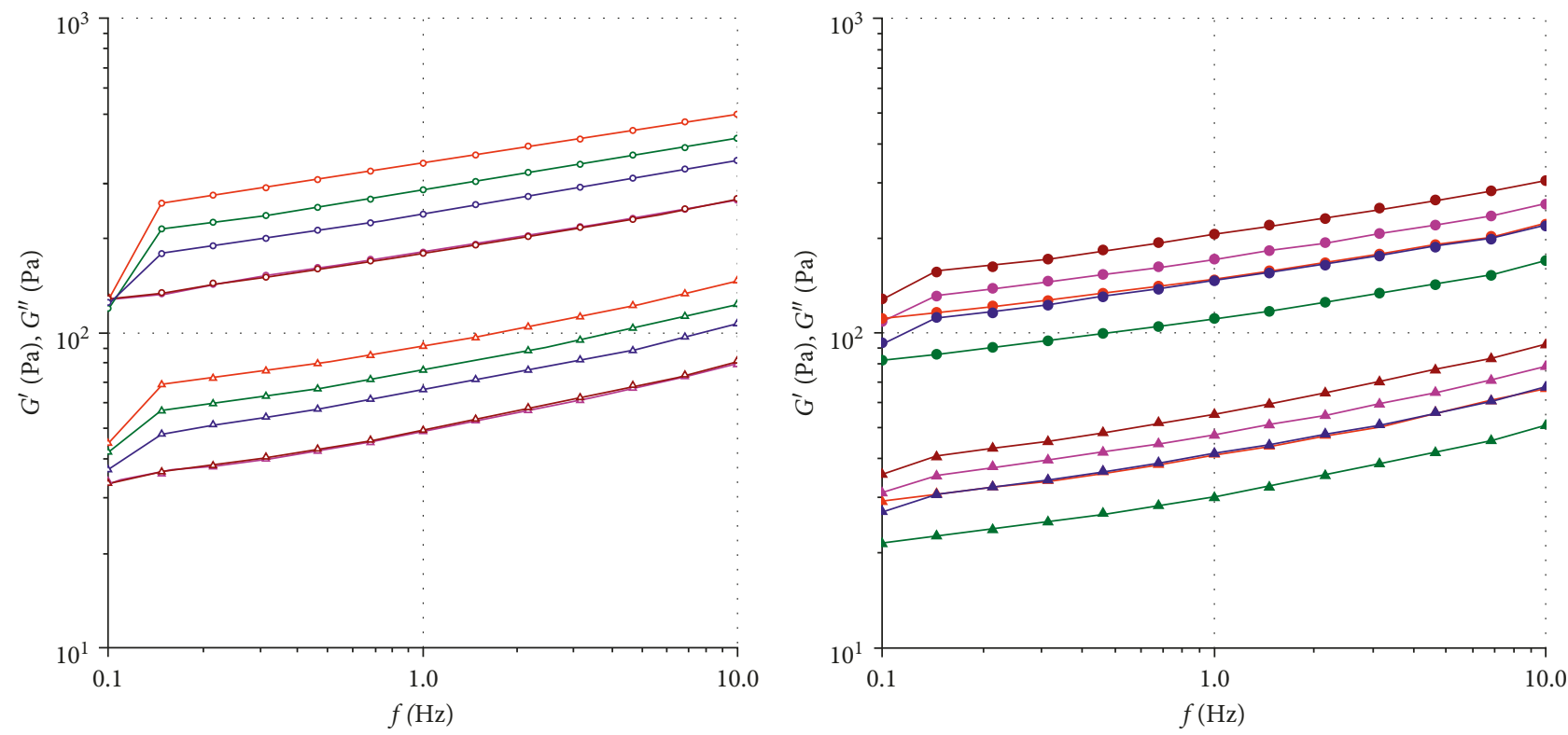

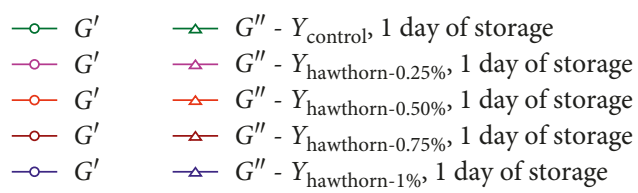

(a)

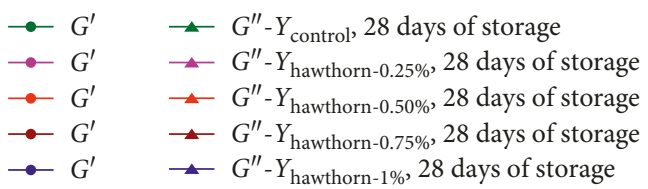

(b)

FiguRE 6: Viscoelastic properties of yogurt with hawthorn (Crataegus monogyna) extract: (a) 1 day of storage; (b) after 28 days of storage. 


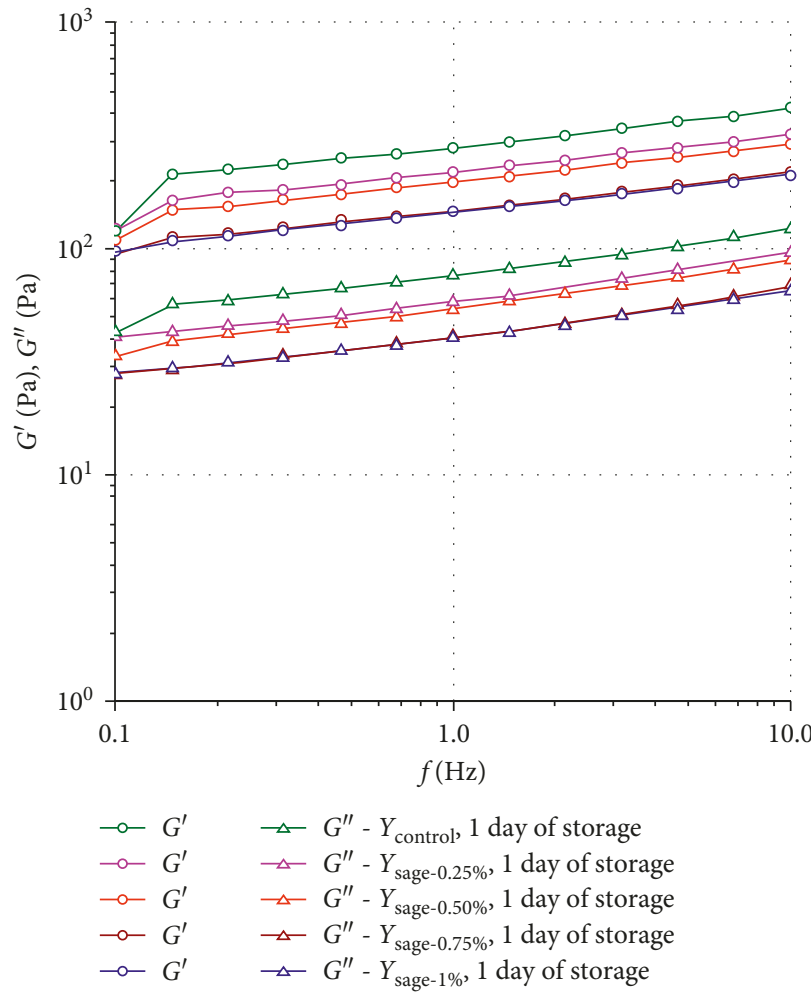

(a)



(b)

FIGURE 7: Viscoelastic properties of yogurt with sage (Salvia officinalis L.) extract: (a) 1 day of storage; (b) after 28 days of storage.


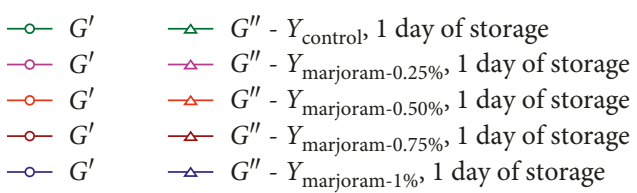

(a)

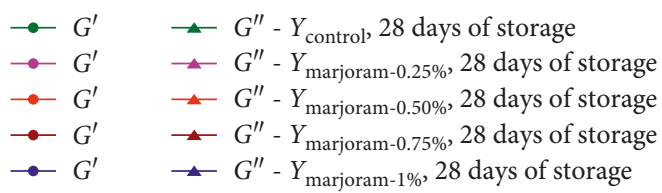

(b)

FIGURE 8: Viscoelastic properties of yogurt with marjoram (Origanum vulgare L.) extract: (a) 1 day of storage; (b) after 28 days of storage. 


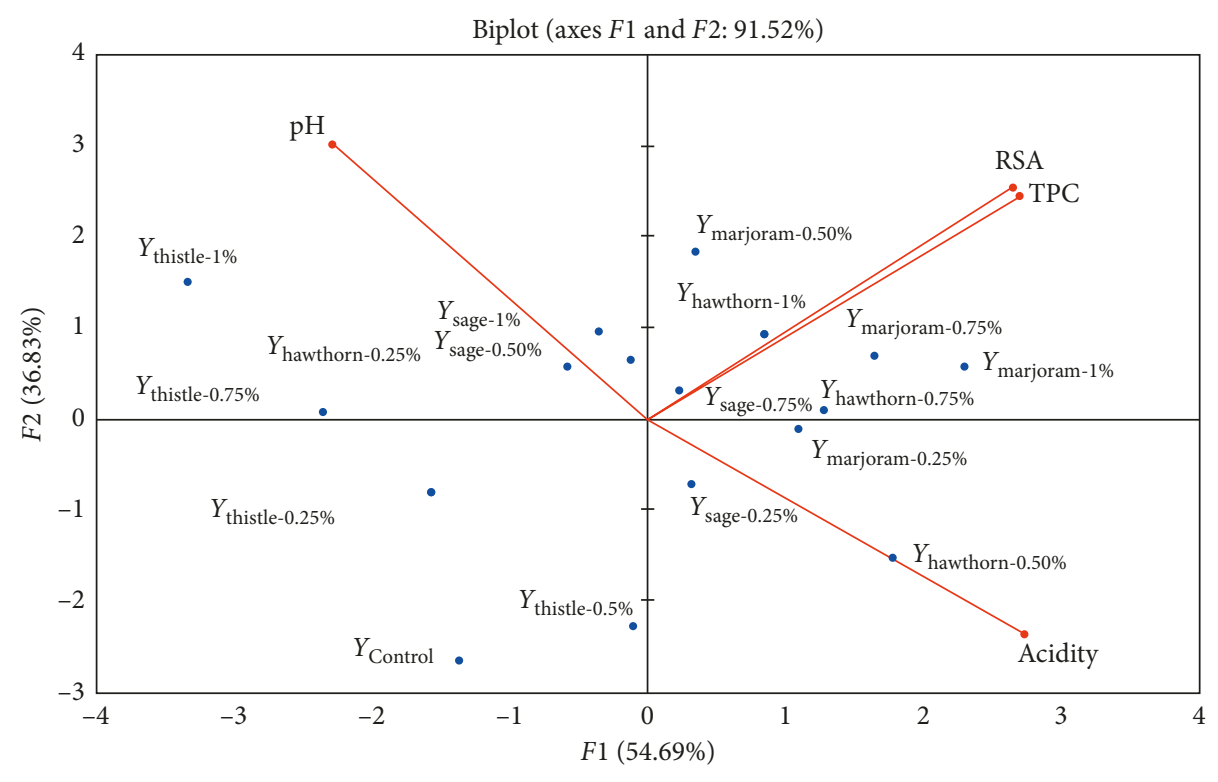

- Active variables

- Active observations

Figure 9: PCA loadings of the yogurt characteristics after 1 day of storage.



Figure 10: PCA loadings of the yogurt characteristics after 28 days of storage.

the antioxidant character of yogurt samples. The acidity of yogurt after a day of manufacture is lower compared to the $\mathrm{pH}$ value. The addition of $0.5 \%$ hawthorn extract influences the decrease of yogurt acidity.

The addition of sage extract in yogurt does not influence the analyzed physicochemical characteristics. This aspect is distinguished by the distribution of values in separate dials and compared to the control sample (without the addition of plant extracts).
The PCA chart at 28 days after yogurt production indicates an increase in acidity in yogurt samples and a decrease in $\mathrm{pH}$ value during storage. The values of the antioxidant activity and the polyphenols content remain high, especially, in the yogurt samples with the addition of marjoram extract. The addition of the hawthorn extract in high amount $(0.75 / 1 \%)$ favors the growth of the antioxidant character. These results are in agreement with those obtained by Shyamala which obtained a stability in time of the yogurt 
samples when different levels of coriander (Coriandrum sativum) and spinach (Spinacia oleracea) extracts were added [42].

\section{Conclusions}

This manuscript demonstrates that extracts from different herbs can be incorporated successfully into a fermented dairy product such as yogurt.

So far, the aqueous extracts obtained from the four plants which are considered in this study, respectively, thistle (Silybum marianum L.), hawthorn (Crataegus monogyna), sage (Salvia officinalis L.), marjoram (Origanum vulgare L.), have not been used in the manufacture of yogurt. The final results show that the physicochemical and rheological properties of the yoghurt with herb extracts addition were improved compared to the control sample after 28 days of storage.

Syneresis and water holding capacity was improved due to the thistle extract (Silybum marianum L.) addition. The best results in terms of antioxidant properties were obtained when marjoram extract (Origanum vulgare L.) was incorporated. The highest rheological values were obtained for the samples with thistle extract (Silybum marianum L.) addition. According to the data obtained, the best quality in terms of the physicochemical and rheological properties was in the case of the sample with $0.5 \%$ thistle extract (Silybum marianum L.) addition, while from the point of view of the nutritional value, the best quality was in the case of the sample with $1 \%$ marjoram extract (Origanum vulgare L.) addition.

\section{Data Availability}

The data used to support the findings of this study are available from the corresponding author upon request.

\section{Conflicts of Interest}

The authors declare that there are no conflicts of interest regarding the publication of this paper.

\section{Acknowledgments}

This work was supported by a grant of the Romania National Authority for Scientific Research and Innovation, CNCS/CCCDI-UEFISCDI, project number PN-III-P2-2.1BG-2016-0089, within PNCDI III.

\section{References}

[1] O. Cueva and K. J. Aryana, "Quality attributes of a heart healthy yogurt," LWT-Food Science and Technology, vol. 41, no. 3, pp. 537-544, 2008.

[2] H. H. Gahruie, M. H. Eskandari, G. Mesbahi, and M. A. Hanifpour, "Scientific and technical aspects of yogurt fortification: a review," Food Science and Human Wellness, vol. 4, no. 1, pp. 1-8, 2015.

[3] C. Caleja, L. Barros, A. Antonio, M. Carocho, M. B. Oliveira, and I. Ferreira, "Fortification of yogurts with different antioxidant preservatives: a comparative study between natural and synthetic additives," Food Chemistry, vol. 210, pp. 262268, 2016.

[4] M. Cossu, C. C. A. Juliano, R. Pisu, and M. C. P. Alamanni, "Effects of enrichment with polifenolic extracts from Sardinian plants on physico-chemical, antioxidant and microbiological properties of yogurt," Italian Journal of Food Science, vol. 21, pp. 447-459, 2009.

[5] M. Karaaslan, M. Ozden, H. Vardin, and H. Tunkoglu, "Phenolic fortification of yogurt using grape and callus extracts," LWT-Food Science and Technology, vol. 44, no. 4, pp. 1065-1072, 2011.

[6] V. Chouchouli, N. Kalogeropoulos, S. J. Konteles, E. Karvela, D. P. Makris, and V. T. Karathanos, "Fortification of yoghurts with grape (Vitis vinifera) seed extracts," LWT-Food Science and Technology, vol. 53, no. 2, pp. 522-529, 2013.

[7] D. Najghebauer-Lejko, M. Sady, T. Grega, and M. Walczycka, "The impact of tea supplementation on microflora, $\mathrm{pH}$ and antioxidant activity of yogurt," International Dairy Journal, vol. 21, no. 8, pp. 568-574, 2011.

[8] A. S. Baba, A. Najarian, A. B. Shori, K. W. Lit, and G. A. Keng, "In vitro inhibition of key enzymes related to diabetes and hypertension in Lycium barbarum yogurt," Arabian Journal for Science and Engineering, vol. 39, no. 7, pp. 5355-5362, 2014.

[9] A. M. O’Sullivan, M. N. O’Grady, Y. C. Callaghan, T. J. Smyth, N. M. O'Brien, and J. P. Kerry, "Seaweed extracts as potential functional ingredients in yogurt," Innovative Food Science and Emerging Technologies, vol. 37, pp. 293-299, 2016.

[10] M. Barkallah, M. Dammak, I. Louati et al., "Effect of Spirulina platensis fortification on physicochemical, textural, antioxidant and sensory properties of yogurt during fermentation and storage," LWT-Food Science and Technology, vol. 84, pp. 323-330, 2017.

[11] A. C. Pelaes Vital, P. A. Goto, L. N. Hanai et al., "Microbiological, functional and rheological properties of low fat yogurt supplemented with Pleurotus ostreatus aqueous extract," LWT-Food Science and Technology, vol. 64, no. 2, pp. 1028-1035, 2015.

[12] P. Muniandy, A. B. Shorib, and A. S. Baba, "Influence of green, white and black tea addition on the antioxidant activity of probiotic yogurt during refrigerated storage," Food Packaging and Shelf Life, vol. 8, pp. 1-8, 2016.

[13] J. M. W. Wibawanti, Rinawidiastuti, H. D. Arifin, and Zulfanita, "Improving characteristics of goat milk yogurt drink fortified by mangosteen rind (Garcinia mangostana Lin.) extract," IOP Conference Series: Earth and Environmental Science, vol. 102, p. 012018, 2018.

[14] N. Ahmad, B. Haider Abbasi, and H. Fazal, "Evaluation of antioxidant activity and its association with plant development in Silybum marianum L.," Industrial Crops and Products, vol. 49, pp. 164-168, 2013.

[15] A. A. Albassam, R. F. Frye, and J. S. Markowitz, "The effect of milk thistle (Silybum marianum) and its main flavonolignans on CYP2C8 enzyme activity in human liver microsomes," Chemico-Biological Interactions, vol. 271, pp. 24-29, 2017.

[16] L. Lucinia, D. Kaneb, M. Pellizzonia et al., "Phenolic profile and in vitro antioxidant power of different milkthistle [Silybum marianum (L.) Gaertn.] cultivars," Industrial Crops and Products, vol. 83, pp. 11-16, 2016.

[17] D. Csupor, A. Csorba, and J. Hohmann, "Recent advances in the analysis of flavonolignans of Silybum marianum," Journal of Pharmaceutical and Biomedical Analysis, vol. 130, pp. 301-317, 2016. 
[18] N. Qin, C. Jia, J. Xu et al., "New amides from seeds of Silybum marianum with potential antioxidant and antidiabetic activities," Fitoterapia, vol. 119, pp. 83-89, 2017.

[19] J. Fibigr, D. Šatínský, and P. Solich, "A new approach to the rapid separation of isomeric compounds in a Silybum marianum extract using UHPLC core-shell column with F5 stationary phase," Journal of Pharmaceutical and Biomedical Analysis, vol. 134, pp. 203-213, 2017.

[20] J. E. Edwards, P. N. Brown, N. Talent, T. A. Dickinson, and P. R. Shipley, "A review of the chemistry of the genus Crataegus," Phytochemistry, vol. 79, pp. 5-26, 2012.

[21] N. Hellenbrand, J. Sendker, M. Lechtenberg, F. Petereit, and A. Hensel, "Isolation and cuantification of oligomeric and polymeric procyanidins in leaves and flowers of Hawthorn (Crataegus spp.)," Fitoterapia, vol. 104, pp. 14-22, 2015.

[22] L. Pengzhan, K. Heikki Kallio, L. Deguo Lü, Z. Chuansheng, and Y. Baoru, "Quantitative analysis of phenolic compounds in Chinese hawthorn (Crataegus spp.) fruits by high performance liquid chromatography-electrospray ionisation mass spectrometry," Food Chemistry, vol. 127, no. 3, pp. 1370-1377, 2011.

[23] E. Shortle, M. N. O’Grady, D. Gilroy, A. Furey, N. Quinn, and J. P. Kerry, "Influence of extraction technique on the antioxidative potential of hawthorn (Crataegus monogyna) extracts in bovine muscle homogenates," Meat Science, vol. 98, no. 4, pp. 828-834, 2014.

[24] W. Tarraf, C. Ruta, A. Tagarelli, F. De Cillis, and G. De Mastro, "Influence of arbuscular mycorrhizae on plant growth, essential oil production and phosphorus uptake of Salvia officinalis L.," Industrial Crops and Products, vol. 102, pp. 144-153, 2017.

[25] Z. Zeković, D. Pintać, T. Majkić et al., "Utilization of sage byproducts as raw material for antioxidants recoveryultrasound versus microwave-assisted extraction," Industrial Crops and Products, vol. 99, pp. 49-59, 2017.

[26] Z. A. Jeshvaghania, M. Rahimmalekb, M. Talebia, and S. A. H. Goli, "Comparison of total phenolic content and antioxidant activity in different Salvia species using three model systems," Industrial Crops and Products, vol. 77, pp. 409-414, 2015.

[27] A. Radwan, M. Kleinwachter, and D. Selmar, "Impact of drought stress on specialised metabolism: biosynthesis and the expression of monoterpene synthases in sage (Salvia officinalis)," Phytochemistry, vol. 141, pp. 20-26, 2017.

[28] E. Sarroua, S. Martens, and P. Chatzopoulou, "Metabolite profiling and antioxidative activity of Sage (Salvia fruticosa Mill.) under the influence of genotype and harvesting period," Industrial Crops and Products, vol. 94, pp. 240-250, 2016.

[29] X. L. Zhang, Y. S. Guo, C. H. Wang et al., "Phenolic compounds from Origanum vulgare and their antioxidant and antiviral activities," Food Chemistry, vol. 152, pp. 300-306, 2014.

[30] B. Lukas, C. Schmiderer, U. Mitteregger, and J. Novak, "Arbutin in marjoram and oregano," Food Chemistry, vol. 121, pp. 185-190, 2010.

[31] M. B. Hossain, N. P. Brunton, A. Patras et al., "Optimization of ultrasound assisted extraction of antioxidant compounds from marjoram (Origanum marjorana L.) using response surface methodology," Ultrasonics Sonochemistry, vol. 19, no. 3, pp. 582-590, 2012.

[32] A. Dabija, G. G. Codină, and A. M. Sidor, "Effect of different fibre addition on the yogurt's quality," in Proceedings of the 17th International Multidisciplinary Scientific GeoConference SGEM, vol. 61, pp. 655-663, Albena, Bulgaria, July 2017.
[33] Z. Maksimović, D. Malencić, and N. Kovacević, "Polyphenol contents and antioxidant activity of Maydis stigma extracts," Bioresource Technology, vol. 96, no. 8, pp. 873-887, 2005.

[34] W. Brand-Williams, M. E. Cuvelier, and C. Berset, "Use of a free radical method to evaluate antioxidant activity," $L W T$ Food Science and Technology, vol. 28, no. 1, pp. 25-30, 1995.

[35] A. M. Sidor, G. Gutt, A. Dabija, E. Todosi Sănduleac, and V. Sidor, "The effect of yogurt enrichment with sea buckthorn powder on its sensory acceptance, rheological, textural and physicochemical properties," in Proceedings of the 17th International Multidisciplinary Scientific GeoConference SGEM, vol. 61, pp. 1117-1128, Albena, Bulgaria, July 2017.

[36] G. G. Codina, S. G. Franciuc, and S. Mironeasa, "Rheological characteristics and microstructure of milk yogurt as influenced by quinoa flour addition," Journal of Food Quality, vol. 39, no. 5, pp. 559-566, 2016.

[37] B. N. P. Sah, T. Vasiljevic, S. McKechnie, and O. N. Donkor, "Physicochemical, textural and rheological properties of probiotic yogurt fortified with fibre-rich pineapple peel powder during refrigerated storage," LWT-Food Science and Technology, vol. 65, pp. 978-986, 2016.

[38] C. Ramirez-Santiago, L. Ramos-Solis, C. Lobato-Calleros, C. Peña-Valdivia, E. J. Vernon-Carter, and J. Alvarez-Ramírez, "Enrichment of stirred yogurt with soluble dietary fiber from Pachyrhizus erosus L. urban: effect on syneresis, microstructure and rheological properties," Journal of Food Engineering, vol. 101, no. 3, pp. 229-235, 2010.

[39] M. Bertolino, S. Belviso, B. Dal Bello et al., "Influence of the addition of different hazelnut skins on the physicochemical, antioxidant, polyphenol and sensory properties of yogurt," LWT-Food Science and Technology, vol. 63, no. 2, pp. 1145$1154,2015$.

[40] T. R. S. Mathias, I. C. Carvalho Junior, C. W. P. Carvalho, and E. F. C. Sérvulo, "Rheological characterization of coffeeflavored yogurt with different types of thickener," Brazilian Journal of Food and Nutrition, vol. 22, no. 4, pp. 521-529, 2011.

[41] T. Sanz, A. Salvador, A. Jiménez, and S. M. Fiszman, "Yogurt enrichment with functional asparagus fibre. Effect of fibre extraction method on rheological properties, colour, and sensory acceptance," European Food Research and Technology, vol. 227, no. 5, pp. 1515-1521, 2008.

[42] B. N. Shyamala, S. Gupta, A. Jyothi, and L. J. Prakas, "Leafy vegetable extracts-antioxidant activity and effect on storage stability of heated oils," Innovative Food Science and Emerging Technologies, vol. 6, no. 2, pp. 239-245, 2005. 


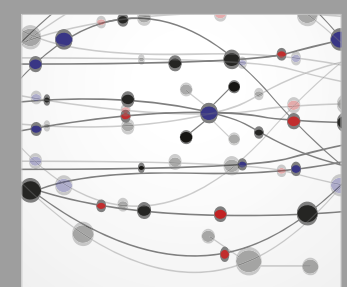

The Scientific World Journal
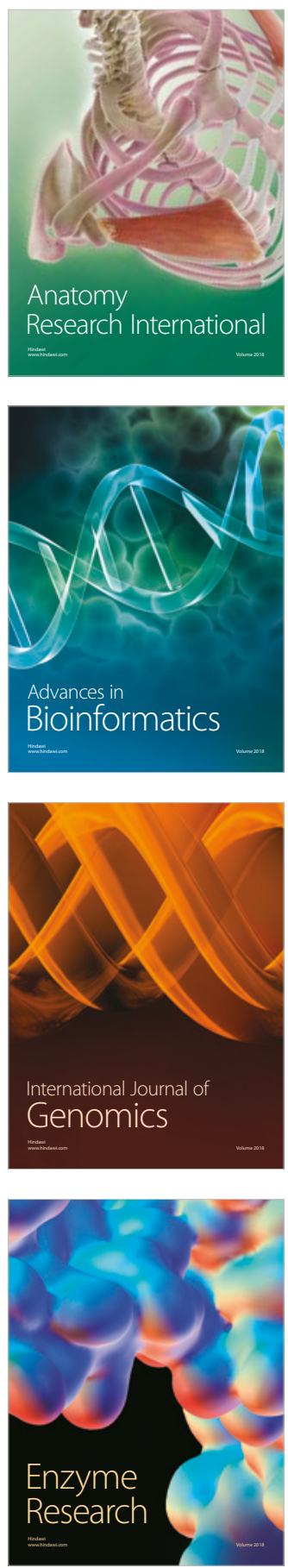
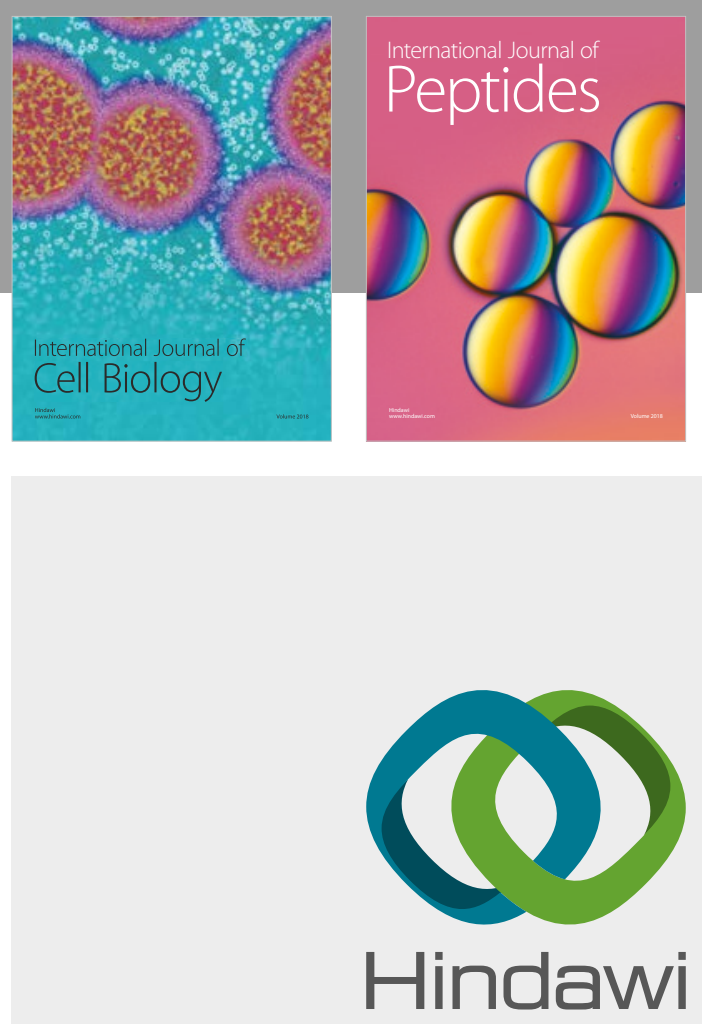

Submit your manuscripts at

www.hindawi.com
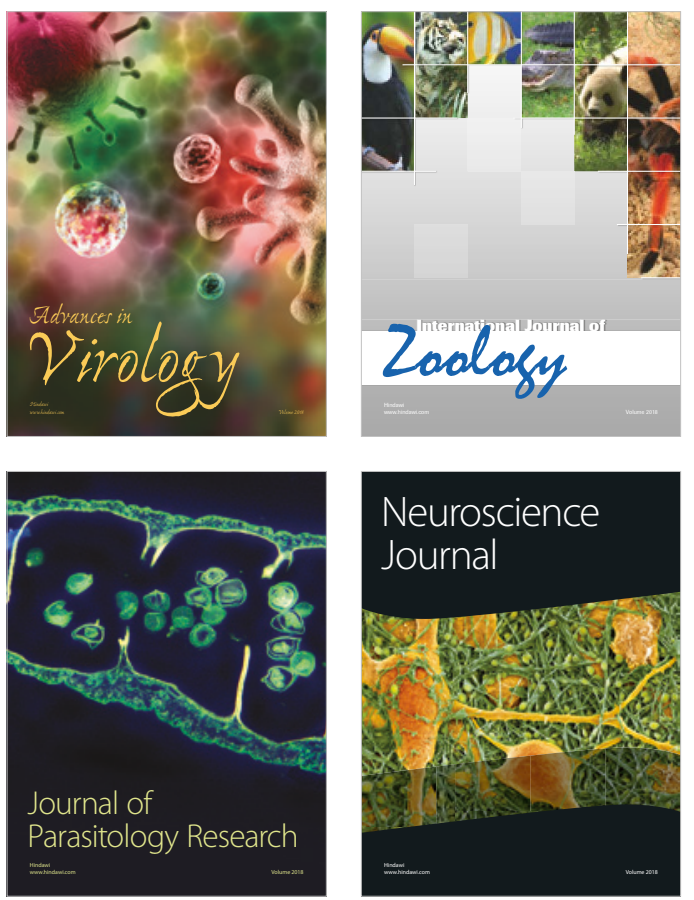
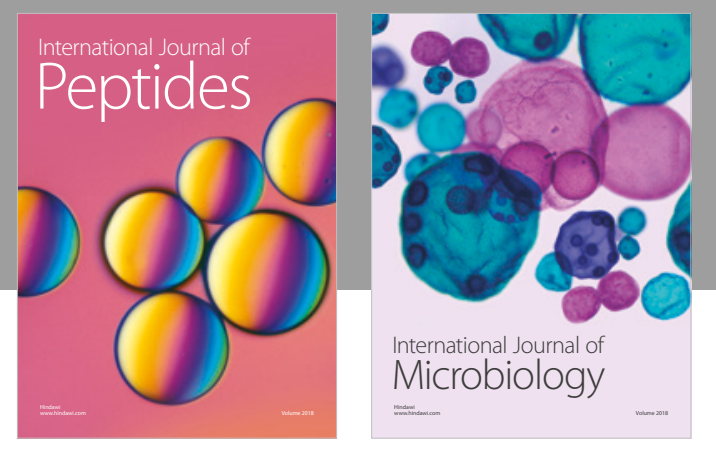

nternational Journal of Microbiology
Journal of
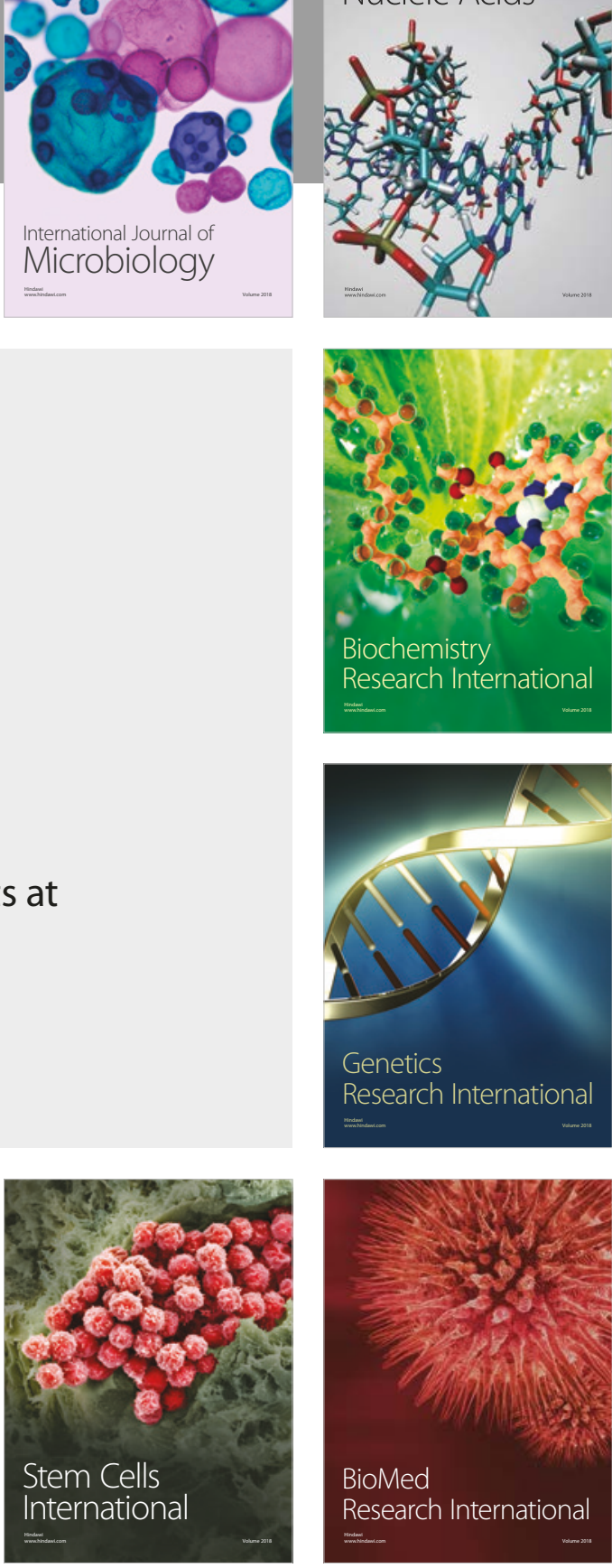
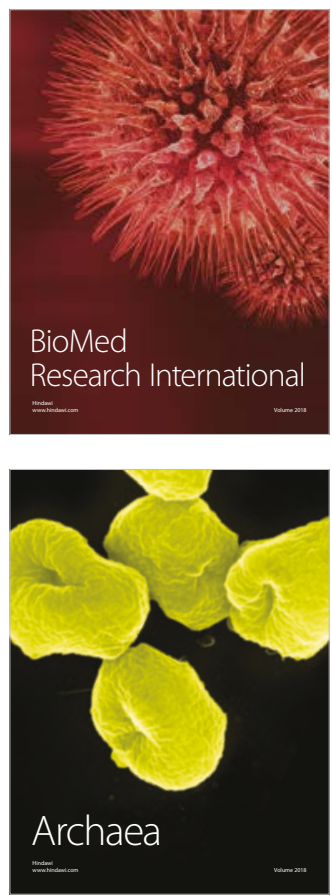